\title{
SANEAMENTO BÁSICO NO INTERIOR PAULISTA - PARALELO ENTRE PRESIDENTE EPITÁCIO E BIRIGUI
}

\author{
Daiane dos Santos Esquevani', Camila Augusta Florindo', Mayara Pissutti Albano ${ }^{2}$ Yeda Ruiz Maria² \\ ${ }^{1}$ Discentes do curso de Arquitetura e Urbanismo da Universidade do Oeste Paulista - UNOESTE. ${ }^{2}$ Docentes dos \\ cursos de Arquitetura e Urbanismo, Engenharia Ambiental e Sanitária, Design de Interior e Engenharia de \\ Produção da Universidade do Oeste Paulista - UNOESTE. E-mail: daiane esquevani@hotmail.com
}

\section{RESUMO}

O bom planejamento urbano ambiental nas cidades é a principal fonte para se evitar o crescimento desordenado da população e do saneamento básico. Esse artigo visa demonstrar a importância de um bom planejamento ambiental nas cidades e uma comparação do saneamento básico de duas cidades no interior do Estado de São Paulo, uma com pequena densidade populacional e outra com média densidade populacional, para uma comparação a fim de notar suas diferenças e igualdades, abrindo uma discussão, onde algumas cidades menores podem ou não possuir uma qualidade de saneamento superior as maiores. Tem como objeto de estudo as cidades de Presidente Epitácio, à Oeste do Estado de São Paulo e Birigui, à Noroeste. Foram realizadas pesquisas bibliográficas e um levantamento dos dados necessários para fazer a comparação entre ambas. Desta forma busca-se contribuir para a discussão aspectos na qualidade de distribuição da água, tratamento de esgoto e coleta de lixo.

Palavras chave: Saneamento Ambiental, Abastecimento de água, Tratamento de esgoto, Coleta de lixo, Planejamento Urbano Ambiental.

\section{INTRODUÇÃO}

O processo de urbanização acelerado e desordenado acarreta em mais poluição, violência e pobreza (GOUVEIA, 1999). É um grande obstáculo da atualidade, pois acentua os problemas de saúde e de qualidade de vida da população.

A degradação do meio ambiente pelo homem é mais nítida em países mais pobres, já que a urbanização ocorre rapidamente muitas vezes não obtendo um planejamento. (GOUVEIA, 1999)

Gouveia (1999) enfatiza que em países mais pobres a urbanização desordenada fez com que ultrapassasse a capacidade financeira e administrativa das cidades em promover uma boa infraestrutura e serviços primordiais como água, coleta e destinação final do lixo, serviços de saúde, além ainda de empregos e moradia.

É sempre a população mais pobre que habita nas periferias dos grandes centros urbanos e em áreas menos privilegiadas que vivem em condições inadequadas de moradia, sem acesso aos serviços básicos e expostas à vários tipos de contaminação, salientando ainda as problemáticas ambientais que o saneamento básico não administrado devidamente pode acarretar (GOUVEIA, 
1999). Estima-se que cerca de $1 / 4$ (um quarto) da população urbana dos países do 3o mundo não têm acesso à água potável (ROSSI-ESPAGNET et al., 1991 apud GOUVEIA, 1999).

No Brasil, a rede de serviços básicos vem se expandindo, porém observa-se que esse crescimento tem sido insuficiente para suprir as sempre crescentes "necessidades básicas da população", em função da urbanização acelerada [...]. (GOUVEIA,1999, p.54)

Gouveia (1999, p.54), ressalta que [...] "mesmo nas regiões com melhores índices de cobertura de serviços de saneamento ainda persistem grandes diferenciais intra-regionais e intraurbanos," ele cita como exemplo o Município de São Paulo que o percentual médio de residências ligadas à rede de esgoto varia de 100\% nas áreas mais ricas e centrais da cidade, até 15\% nas áreas mais pobres da periferia (JACOBI, 1990 apud GOUVEIA, 1999).

Por isso um bom planejamento urbano ambiental nas cidades é a principal fonte para se evitar o crescimento desordenado da população e do saneamento básico.

Assim sendo o objetivo desta pesquisa é levantar a situação atual do saneamento básico e como o mesmo está sendo aplicado nas cidades de Birigui - SP e Presidente Epitácio - SP.

A metodologia de pesquisa foi baseada em pesquisas bibliográficas, documentais e de campo. As pesquisas de campo incluíram levantamentos in loco e nos setores de planejamento das Prefeituras e concessionárias.

\section{SANEAMENTO BÁSICO EM PRESIDENTE EPITÁCIO E BIRIGUI - BREVE CARACTERIZAÇÃO}

O município de Presidente Epitácio se localiza na porção oeste do estado de São Paulo, à margem esquerda do rio Paraná, contendo uma área de aproximadamente $1281,78 \mathrm{~km}^{2}$. A cidade de Birigui, segundo o site oficial da Prefeitura Municipal, situa-se na Região Noroeste do Estado de São Paulo, pertencente à Macrorregião de Araçatuba, distante $521 \mathrm{Km}$ da Capital, possui uma população de mais de 110.911 habitantes segundo os dados do IBGE (2009) dos quais, 100.522 moram na zona urbana e 2.872 na rural.

O município de Presidente Epitácio é composto por áreas urbanas e o distrito do Campinal e por agrovilas I, II, IV, V, que são assentamentos rurais, além de algumas propriedades agrárias particulares, (PREFEITURA MUNICIPAL DA INSTÂNCIA TURÍSTICA DE PRESIDENTE EPITÁCIO, 2006)

Consta no IBGE (2013) que atualmente Presidente Epitácio conta com 41.318 habitantes.

Segundo Santos e Leal (2008), em Presidente Epitácio o órgão responsável pelo abastecimento de água, e tratamento de esgoto é a Companhia de Saneamento Básico do Estado 
de São Paulo - SABESP, já na cidade de Birigui esses serviços são realizados pelo Sistema de Água e Esgoto - SAEB.

Segundo dados do site da SABESP, em 2012, o município de Presidente Epitácio possuía aproximadamente 14.557 ligações de água, o que corresponde a quase $100 \%$ da cobertura. 0 abastecimento da cidade é todo proveniente do rio Paraná e a quantidade de água tratada é de $7.500 \mathrm{~m}^{3}$, e $6.100 \mathrm{~m}^{3}$ são utilizados por dia.

A cidade de Birigui possui cerca de 37.124 ligações de água, segundo dados do site da Prefeitura Municipal de Birigui, onde a fonte principal é o manancial superficial Ribeirão Baixotes, que possui barragem e é usado desde a década de 60. Além deste, existem dois poços artesianos com 1200 metros de profundidade que estão sendo usados desde 1994 (SAEB, 2013). Já no município de Presidente Epitácio possuem 13 poços que são utilizados pela Santa Casa, postos de gasolina e vários tipos de indústrias. Acredita-se que ainda existam outros poços não conhecidos no município, porém todos descartam os resíduos líquidos na rede coletora de esgoto da cidade (SANTOS ; LEAL, 2008).

Apesar dos poços da cidade de Birigui terem uma boa estrutura, ainda há alguns bairros próximos o SAEB que sofrem com a falta de abastecimento em algum período do dia pela justificativa de necessidade de manutenção, e a consumação é de aproximadamente $25.000 \mathrm{~m}^{3}$ por dia (SAEB, 2013).

Santos e Leal, (2008), afirmam que o tratamento de esgoto estabeleceu-se na cidade de Presidente Epitácio em novembro de 1998, e na atualidade a eficiência do tratamento é de 88,75\%. O sistema de tratamento é do tipo Lagoa anaeróbica, que conta com uma lagoa de Estabilização, e também com 11 estações elevatórias de esgoto no município. As ligações de esgoto existentes em 2012, segundo o site da SABESP, são de 13.012, estimando-se que mais ou menos $6 \%$ da cidade não possui rede coletora de esgoto.

Diferentemente da cidade de Presidente Epitácio, segundo o órgão responsável pelo saneamento básico na cidade de Birigui SAEB (2013) existem 39.057 ligações de esgoto na cidade, e o sistema de tratamento de esgoto é composto por cinco Lagoas de Estabilização que foram criadas em 2012 e tem 82\% de eficiência. A ETE Estação de Tratamento de Esgoto - ETE coleta $22.000 \mathrm{~m}^{3}$ de esgoto diariamente e essa mesma quantia é tratada e despejada no rio Ribeirão Baixotes. A Demanda Bioquímica de Oxigênio (DBO) de entrada corresponde à $261 \mathrm{mg} / \mathrm{l}$ e a de saída, 33 mg/I (SAEB, 2013). Já a DBO de entrada do município Presidente Epitácio é de $320 \mathrm{mg} / \mathrm{l}$ e a DBO de saída é de $36 \mathrm{mg} / \mathrm{l}$. (SANTOS; LEAL, 2008) 
O corpo receptor dos esgotos no município de Presidente Epitácio é o rio Paraná, que atualmente se enquadra na classe 2 do CONAMA, ou seja, serve para o abastecimento de consumo humano (SANTOS ; LEAL, 2008). Entretanto o Ribeirão Baixotes em Birigui, onde não há nenhum tipo de atividade, é a principal fonte de coleta de água e também para o despejo de água do esgoto depois de tratada, ou seja a água que é jogada neste é a mesma retirada para o consumo (SAEB, 2013).

Um dos grandes problemas no município de Presidente Epitácio, segundo Santos e Leal (2008) é o gerenciamento do lixo, pois inicialmente o lixo era jogado no rio Paraná ou em outras localidades, já com o passar do tempo o lixo mudou de endereço, passou a ser descartado em um lixão a céu aberto, próximo ao rio. A partir de 1999 o lixo começou a ser depositado em um aterro controlado, há aproximadamente $6 \mathrm{~km}$ da cidade, transformando o antigo lixão em um local sem uso até os dias de hoje, apenas com sua vegetação crescendo gradativamente ( SANTOS; LEAL, 2008).

Em Birigui a destinação do lixo era semelhante. Hoje no local há plantação de eucaliptos. O Aterro Sanitário Municipal da cidade de Birigui possui o IQR (Índice de Qualidade de Aterro de Resíduos) dado pela CETESB (Companhia de Tecnologia de Saneamento Ambiental) nos últimos três anos foi, respectivamente, 9.5, 9.7, 9.8. (SAEB, 2013). Já o IQR do município de Presidente Epitácio foi avaliado no ano de 2005 em 7,4; 7,4 ainda em 2006 e abaixando para 5,6 em 2007, necessitando-se de melhorias para sua adequação, tendo em vista que os índices variam de 0 a 10. (SANTOS; LEAL, 2008) Com relação aos lixos hospitalares, estes são coletados das farmácias, Santa Casa (60\%), laboratórios, e incinerados na própria área do aterro controlado, e os óleos de automóveis e caminhões, existem 5 empresas que recolhem os mesmos diretamente dos postos de combustível para reciclagem (SANTOS; LEAL, 2008).

Em Presidente Epitácio, segundo os autores Santos e Leal (2008) após o fechamento do lixão, a Prefeitura Municipal teve a iniciativa de implantar a coleta seletiva de lixo domiciliar na cidade, para ajudar as pessoas que trabalhavam no local.

Com o convênio do Comitê da Bacia Hidrográfica do Pontal do Paranapanema - CBH-PP foi criado um barracão de $400 \mathrm{~m}^{2}$ junto ao aterro controlado, foram também compradas prensas e uma esteira móvel de catação, como também a perfuração de um poço semi-artesiano. Assim formou-se a Associação dos Catadores de Presidente Epitácio - ARPE, que recebe auxílio da Prefeitura Municipal, mas tem autonomia nas decisões sobre o processo de coleta, através de seu estatuto próprio. 
Um dado positivo sobre a destinação do lixo em Birigui é que a maioria destes tem a destinação certa, sendo que apenas 3\% dos recicláveis vão para os aterros. Não há usina de triagem, apenas "catadores" que recolhem nas ruas e pedem nas casas materiais recicláveis para vender (PREFEITURA MUNICIPAL DE BIRIGUI, 2013).

Segundo a Prefeitura Municipal de Presidente Epitácio, são produzidas diariamente 30 toneladas de lixo por dia na cidade, e recolhida pela coleta seletiva cerca de 9 toneladas de material para reciclagem por dia, aumentando assim a vida útil do aterro controlado em até $40 \%$. A coleta seletiva recolhe o material reciclável uma vez por semana na área urbana, e uma vez a cada 15 dias na área rural, já a coleta do lixo comum é feita três vezes na semana, e na avenida principal a coleta é feita todos os dias da semana, exceto domingo.

$\mathrm{Na}$ cidade de Birigui não há coleta seletiva como citado acima e são produzidas 93 toneladas de lixo diariamente que são coletadas pela Prefeitura e levadas ao Aterro Sanitário Municipal, dados fornecidos pela Prefeitura Municipal da cidade diz que há um estudo da possibilidade do aproveitamento do gás gerado no local para fornecimento de energia. A frequência da coleta é quase a mesma de Epitácio, sendo diariamente na região central e três vezes por semana nos outros bairros (PREFEITURA MUNICIPAL DE BIRIGUI, 2013).

Outra necessidade é a busca de outro local para o aterro controlado, que deve ser adequada, porém a negociação com proprietários rurais está difícil, já que eles não querem vender nenhuma área para esse fim, e por fim precisa-se pensar na destinação de pneus, que são recolhidos 800 mensalmente no município e guardados em um depósito aguardando seu destino final (SANTOS; LEAL, 2008). Ainda existem diversos desafios para o lixo de Presidente Epitácio, principalmente em relação aos resíduos do sistema de saúde.

\section{CONSIDERAÇÕES FINAIS}

Conclui-se, portanto que em relação à destinação do lixo, apesar da cidade de Presidente Epitácio parecer ter uma melhor coleta, sua destinação final não tem sido apropriada diferente de Birigui que não possui o serviço de coleta seletiva, mas como dito anteriormente apenas $3 \%$ de lixo reciclável vão para o aterro, tendo os outros tipos de lixo a destinação correta tornando o aterro desta ultima cidade melhor qualificado.

Considerando a pesquisa comparativa realizada no presente trabalho, pode-se perceber que, em relação ao abastecimento de água Presidente Epitácio, apesar de possuir menos habitantes do que Birigui, em proporção, possui maior cobertura do abastecimento a população. 
A coleta do lixo é semelhante nas duas cidades, que contam com aterros sanitários avaliados pela CETESB, tendo em Presidente Epitácio uma coleta seletiva, que auxilia as pessoas que trabalhavam no antigo lixão da cidade, o que não acontece em Birigui, que é uma cidade maior.

Analisando a situação do saneamento básico nas duas cidades foi possível entender melhor o funcionamento de cada localidade e perceber como existem diferenças em distancias tão pequenas.

Com o Planejamento Urbano Ambiental todos os problemas de saneamento básico como, destinação correta do lixo, ligação de água e esgoto para toda população poderiam ser evitados trazendo para as cidades e para a população uma melhor qualidade de vida, pois toda e qualquer ação realizada sem um planejamento, há consequências tanto para o meio ambiente quanto para o ser humano. O planejamento serve para tentar evitar as consequências catastróficas que surgem com o tempo quando não se há um estudo antecipado das ações. Ele é o principal instrumento para se evitar um crescimento desordenado nas cidades, propiciando a saúde do meio ambiente e locais melhores para se viver.

\section{REFERÊNCIAS}

CÂMARA MUNICIPAL DE BIRIGUI. Disponível <http://www.camarabirigui.sp.gov.br/historia/fotos-historicas/mapa.png/view>. Acesso em 17 de abril de 2013.

PREFEITURA DA INSTÂNCIA TURISTICA DE PRESIDENTE EPITÁCIO. Disponível em <www.presidenteepitacio.sp.gov.br>; Acesso em 17 de abril de 2013.

PREFEITURA MUNICIPAL DE BIRIGUI. Cidade. Disponível em <http://www.birigui.sp.gov.br/birigui/websites/prefeiturabirigui/site/cidade/cidade dados.php>; Acesso em 17 de abril de 2013.

SABESP. Companhia de Saneamento Básico do Estado de São Paulo. Disponível em < http://site.sabesp.com.br>. Acesso em 17 de abril de 2013.

SAEB - Sistema de Água e Esgoto de Birigui. Cidade. 2013.

SANTOS, Ricardo ; LEAL, Antonio Cesar. Análise ambiental da Instância Turística de Presidente Epitácio - São Paulo - Brasil. Dissertação de Mestrado em Geografia. Universidade Estadual Paulista Júlio de Mesquita Filho - UNESP Presidente Prudente, 2008.

GOUVEIA, Nelson. Saúde e Meio Ambiente nas cidades: os desafios da saúde ambiental - São Paulo - Brasil. 1999, 61f. Artigo Científico, Faculdade de Medicina da Universidade de São Paulo. 
Encontro de Ensino, Pesquisa e Extensão, Presidente Prudente, 21 a 24 de outubro, 2013

Disponível em < http://www.scielo.br/pdf/sausoc/v8n1/05.pdf $>$. Acesso em: 05 de agosto de 2013.

IBGE - Instituto Brasileiro de Geografia e Estatística. Disponível em $<$ http://www.ibge.gov.br/cidadesat/painel/painel.php?codmun=354130>Acesso em: 05 de agosto de 2013. 